\title{
Back to the Individual: on the educational importance of commitment
}

\section{PAUL SMEYERS}

The Ethics of Authenticity. Charles Taylor, 1991, Harvard, MA: Harvard University Press pp. viii +142 , pbk $£ 11.50$

Multiculturalism and the Politics of Recognition. An essay by Charles Taylor with commentary by Amy Gutmann, Steven C. Rockefeller, Michael Walzer and Susan Wolf, 1992, Princeton, NJ: Princeton University Press pp. xi +112 , hbk $\mathfrak{£ 2 5}$

The Canadian philosopher Charles Taylor is widely known in the field of 'pure' Philosophy as well as within the Social Sciences. His Explanation of Behaviour (1964), Philosophy and the Human Sciences (1985) and particularly The Sources of the Self: The Making of the Modern Identity (1989), by many regarded as essential for understanding today's debates, are widely studied also within the educational field. The two recent publications that are dealt with here have to be understood in the light of earlier writings.

In earlier publications he had argued that to be a full human agent, ‘. . to be a person or self in the ordinary meaning, is to exist in a space defined by distinctions of worth. A self is a being for whom certain questions of category value have arisen, and received at least partial answers. Perhaps they have been given authoritatively by the culture more than they have been elaborated in the deliberation of the person concerned, but they are his in the sense that they are incorporated into his selfunderstanding, in some degree and fashion' (Taylor, 1985, p. 3). The Ethics of Authenticity on the other hand deals with what is indicated by many as the heart of the malaise of modernity: the concept of 'authenticity' or 'self-realisation'. Though Taylor recognises the dangers that go with this pursuit (such as rendering ineffective the whole tradition of common values and social commitment), he tries to show how, rightly conceived, 'being authentic' is the antidote against the loss of meaning and of shared values, because, so he claims, human beings can simply not exist with such losses. At the level of education this means that children can be initiated into particular values and that many of the postmodernists' conclusions have to be repudiated.

After raising some doubts about Taylor's recent claims concerning the concept of a human being, it is argued here that though he cannot convince those who do not already share his basic idea of a person, he indicates nevertheless something extremely 
important within the context of education. The quest for authenticity, understood as veracity and as integrity, turns out to be at the very heart of any educational enterprise.

In the Ethics of Authenticity (1991) 1 Taylor deals with three 'worries': individualism, the primacy of instrumental reason and the feared consequences of the latter for political life. Though individualism also names what many people consider the finest achievement of modern civilisation - the right to choose for themselves their own pattern of life - and very few people want to go back on this achievement, many are also ambivalent. Modern freedom presupposed breaking loose from older moral horizons which, though they restricted us, gave meaning to the world and to the activities of social life. This broader vision was lost because people focused on their individual lives. Here the dark side of individualism came forward, the centring on the self that both flattens and narrows our lives. This disenchantment of the world is connected with the primacy of instrumental reason. Instrumental reason in one sense is liberating, though in another it threatens to take over our lives, as the independent ends that ought to be guiding our lives can be eclipsed by the absorbing problems of adjusting means to ends, ends that can lapse, in default of debate, into the status of axioms. The consequence can be a great loss of freedom. It is hard for individuals to find a new form of the broader vision they need to give meaning to their lives and activities, as considering their values and goals requires that they place themselves outside a climate of instrumental reason; and this is difficult in a pervasively instrumentalist society. Furthermore very few will want to participate actively in selfgovernment: 'They will prefer to stay at home and enjoy the satisfactions of private life, as long as the government of the day produces the means to these satisfactions and distributes them widely' (p. 9). A rather facile relativism prevails, where everyone has his or her own 'values' about which it is impossible to argue. This is more a moral than an epistemological position: others' values are their concern, their life choice, and this situation ought to be respected. It is an offshoot of a form of individualism in which everyone has a right to develop their own form of life, grounded on their own sense of what is really important or of value, and consequently people are called upon to be true to themselves and to seek their own self-fulfilment. Though this relativism is, according to Taylor, a profound mistake, even in some respects self-stultifying, there is a powerful moral ideal at work behind self-fulfilment, namely that of being true to oneself.

Can one say anything to any point to people who are immersed in the contemporary culture of authenticity and can one talk to those who are deeply into relativism about values, Taylor asks. No, so he claims: 'A person who accepted no moral demands would be as impossible to argue with about right and wrong as would a person who refused to accept the world of perception around us be impossible to argue with about empirical matters' (p.32). He is invoking as a general feature of human life its fundamentally dialogical character. We are introduced into the languages needed for self-definition through exchanges with 'significant others'. This self-definition always works in dialogue with, sometimes in struggle against, the identities significant others want to recognise in us. Taylor tries to show that modes of self-definition '... that opt for self-fulfilment without regard (a) to demands of our ties with others or (b) to demands of any kind emanating from something more or other than human desires or aspirations are self-defeating, that they destroy the conditions for realizing authenticity itself' (p.35). His central argument to substantiate these claims answers the question of what it is to define ourselves. If we are to determine in what our personal originality consists, '. . . we see that we have to take as background some sense of what is 
significant' (p. 35). And that is exactly what is missing in the slide towards relativism. Things do not have significance in themselves nor can people determine what is significant '. . . either by decision, or perhaps unwittingly and unwillingly by just feeling that way' (p. 36). In order to be able to escape the arbitrariness of moral relativism, we need a criterion for choice. It is not just because something is freely chosen that it is a kind of choice that confers worth. A pre-existing horizon of significance is needed. In other words, understanding self-determining freedom is dependent upon there being, independent of my will, something noble, courageous and hence significant in giving shape to my own life. In a similar way Taylor develops an argument against attributing purely instrumental significance to the various associations and communities into which a person enters. One again arrives at the acknowledgement that our identity requires recognition by others.

Let me introduce my discussion of Taylor's insights by reference to what I consider an outstanding example for the matter that he wants to raise. In 'The Crying Game', Neil Jordan's recent film (1992), Fergus, a member of the IRA, falls in love with the 'girlfriend' of a British soldier. This soldier had died in the course of events when he was a hostage and Fergus one of the kidnappers. 'The girl-friend' turns out to be a 'he', and when this person kills another woman who, even more than Fergus, is responsible for the death of the hostage, Fergus takes the blame on himself and spends years in jail in her place. Why does this man do something like that? Why does he serve 'her' time? Well, he promised the British soldier that he would look his 'girfriend' up and look after 'her', and that he would make sure that everything was all right. It is important to point out that despite a lot of effort Fergus does not manage to fall in love with 'her', though he does love 'her' dearly. One could well ask, 'Is this the behaviour of a fool?' In my opinion the answer to this question must be negative. Keeping one's word and taking responsibility no matter what that demands, doing what needs to be done in the situation one finds oneself in, presupposes a particular concept of a 'person'. Such a person will display at least a relative consistency and unity. Such a person would be capable of saying, "If I do not do this or that, I will not be able to live with myself anymore'. It resembles the more common experience of being committed to a friend who does something special for us or of doing what one promised to someone who is dying. In the example given, some things are important for Fergus, and remain so no matter what the consequences are. Moreover, Fergus experiences this as his own decision. The leading character within this story is in some sense an authentic individual. $\mathrm{He}$ acts for reasons that are also his reasons, though they are undoubtedly constituted and embedded within a particular society and community.

Such authenticity is no longer recognised within a certain kind of philosophy of education. Some postmodernist authors claim that there is no point left for such a concept of responsibility. They no longer accept that people are responsible for what they do, as in a strong sense first they do not know what they are doing, and second they do not have any grasp of the consequences. The concept of a 'person', which appears to oneself as a relative unity, has been given up in this nihilistic kind of postmodernism. The claim is that education, and consequently philosophy of education, have lost their identity. On the one hand shared values have disappeared at the societal level, and people do not 'know' anymore what is right and wrong; on the other hand the individual has evaporated. Authors who defend these ideas and proclaim the end of education can be found both within Anglo-Saxon Philosophy of Education (see for instance Kiziltan et al. 1990) and within its Continental counterpart 
(see for instance Giesecke, 1987). Charles Taylor is pre-eminent among those who have responded to this position.

I indicated earlier that Taylor's insight into the origin of the idea of authenticity, together with his indication of modernity's problems, is also a plea for the promotion of a specific kind of human being and a specific kind of society. Taylor reminds us of some Wittgensteinian basic ideas, for instance that there is a difference between genuinely 'following a rule' and merely thinking or meaning that one is acting according to it. In the context of Taylor's argument, this seems to imply that the blurring and finally the loss of the distinction between 'being right' and 'thinking/meaning that one is right' leads to relativism. But though it is in principle conceivable that we could value other things than we do, and moreover that our choices cannot be decided once and for all, actually we each exist only in relation to others and thus enmeshed within a whole matrix of value-distinctions, which are crucially important for each of us. If this is so, then one cannot seriously claim that a person does not 'know' what is right or wrong if he doesn't understand the appropriate ontological presuppositions. On the contrary, a person knows what is 'right' and 'wrong' as a matter of course. And moreover the metaphysical justification of his judgements is irrelevant, if indeed there is any such justification. Taylor's moral ideal relates to a concept of authenticity, rightly understood. It is simultaneously characterised by an acceptance of a horizon of meaning, on the basis of which choices can be made, and by an appeal to the transcendent, to that which surpasses the individual. So far so good, one could say, but there are, I'm afraid, some questions left.

Within a rational or philosophical discussion it may seem that nothing can be brought against Taylor's rebuttal of moral relativism. However, it is questionable whether self-discovery within a rational discussion, being borne in a discourse with others, is a way of being which necessarily characterises our kind or must do so continuously and whether it is necessarily superior to a monological one. At least as a matter of fact it is the case that a number of people claim that things are different for them. They state that their values are not open to questioning by others, the limit on their autonomy being only the safe-guarding of their fellow human beings. Thus, at the beginning of 1993, President Clinton said that an appropriate person to be High Court Judge surely has to have a high regard for privacy; and by 'privacy' he was referring to just such autonomy with regard to the values people choose to live by. One could therefore argue that some people in certain cases do not make a choice at all. Maybe they just do something, with which they are perhaps pleased afterwards. It might be objected that this is impossible, because an implicit criterion, a standard, must be involved - and where would that suddenly come from? But that seems to me to go too far, given that our human existence is also determined in a physico-chemical way, but also that we do not always accept our society's standards. The objection would imply that there has to be some post hoc judgement (though this is not actually necessary), as just doing something may also generate approval (for instance on the basis of agreeable experience or in terms of power). To complain that this denies intersubjective embeddedness is not necessary. This dimension is not always denied in all cases. And the 'error' Taylor referred to concerning a person who accepts no moral demands, in his opinion analogous to the person who refuses to accept the world of perception around us in a discussion about empirical matters, seems to me to be of a different kind.

The impossibility of seeing without restraint whatever one wants and the impossibility of just choosing what shall count as right or wrong are not alike. 
Taylor states that there is a similarity between a person who rejects all our perceptual judgements and a person who would accept no moral demands, but in fact refers (in a previous sentence) to '. . . talking to someone who recognized no moral demands whatever' (p. 32, my italicising). And though there is a similarity it seems that concerning the ethical, one is more inclined to ask for a specification of the moral demands. Without filling that in properly, the discussion seems to proceed in an 'idle' way. In the case of the ethical, it is not so much that one does not recognise any 'moral demands', but that one doesn't accept particular moral demands, so that the norms we each accept can be to a much larger extent different from each other.

Here Taylor fills in a particular content and in this sense determines (already) right and wrong. But he does so by recourse to rhetoric rather than argument. He implies for instance that people who refer to 'their own values' are indeed probably mistaken, in the sense that they cannot generate these ex nihilo; and Taylor is right, furthermore, in saying they are in error concerning the possibility of a radical split with the past. But he fails to see that it is not inconceivable that through a number of activities (followed by decisions) they could come up with some radically new position that is very far removed from what is held by most people. And why should they bother about not being able to argue about it? Perhaps it is not so much that they are not willing to argue, but that they circumscribe the domain which they are prepared to argue about with others. Taylor might want to agree with that, but if he does so, then forms of presentday culture which he calls 'narcissistic' do not seem evidently inadequate. However, no educational implication follows from what Taylor would argue here.

I return to what one might argue positively. Perhaps these persons do not want to choose, do not want to justify what they do, and perhaps they do not need to do so. In today's society it is possible to give shape to one's own life the way one wants, given a high degree of individual economic independence and, at least in Western Europe, the safety net of the welfare state. To argue that a horizon of meaning is necessary to make a choice is logically, of course, true. But given that the position discussed above (leave me to do my own thing') is taken by a number of people, it is possible to argue that that position may not be a choice, but just something people do - not necessarily (but possibly) in conflict with other people or knowing what it is that one wants in particular or is striving for. This could be interpreted as a radicalisation of the Sartrean position. That it would be empirically not possible, seems to me manifestly wrong. One can of course discern that such a way of life exhibits schizophrenic features, but as this judgement would appeal to values extraneous to such a way of life, this is not a strong argument. That leaves us the question whether someone might not want to justify herself, neither towards others nor in another sense towards herself concerning the choices she makes. This would indeed be an extremely peculiar person who probably would not converse a lot with others. In fact, if she is not labelled by others ' $a$ fool', she definitely is a very lonely individual. In its extreme form this is of course inconceivable.

A great risk is involved though, if, on the basis of the extreme case, one denies the very possibility of not wanting to choose. It does not seem to me inconceivable that, with regard to certain matters and moreover on certain occasions, people just do what they do, just act. To deny that is to hold too rationalistic a vision of humanity. It is not inconceivable that in certain matters, and temporarily, people behave as if isolated from others. And if that is possible there can indeed be a flaw in Taylor's idea of the horizon of meaning. Put more simply, ethical relativism does not refute itself. Taylor's argument shows that human existence is only typically dialogical, thus it does not rule out the 
possibility of a monological form of existence that would be parasitic on the more typical dialogical form. Granted, my argument rests on the empirical fact that people behave sometimes in this manner - though perhaps not as rarely as I have supposed for the sake of the argument. This argument cannot be dismissed on the ground of the alleged distinction between 'what is' and 'what ought to be the case', because, as Wittgenstein has overwhelmingly demonstrated, they have to be conceived as interwoven. Finally, to object that no one denies that people sometimes just act would misrepresent what has been argued here. It is not so much that people sometimes just act that is the issue here, but the implication this has for the very concept of a human being.

A second difficulty in Taylor's position is linked to the issue of our longing for recognition from each other. Incidentally, it is essential to see both of the outlined queries together. 'Due recognition ...', Taylor argues, ' . . is not just a courtesy we owe people. It is a vital human need' (Taylor, 1992, p. 26). One can easily agree with this Lacanian-Hegelian position. But again we are confronted with a complexity: it has to be decided who precisely these significant others are. Not that we can choose them freely, but neither is it the case that we have no choice in the matter at all. Even if our parents can hardly lose their position as significant others, this is less true of the relationships we have 'freely' chosen - though often for a non-specified longer period. Wringe for instance argues for a review of family patterns. The basic unit, he states, '.. may be the individual whose linkages with others, however weak or strong, however stable or transient, are essentially undetermined and susceptible of renegotiation' (Wringe, 1993, p. 75).

Again let me put this more clearly. It is not so much that one can choose who significant others are or who will become significant for us, but that their places are taken by others as a matter of course if they more generally do not fulfil their role as satisfiers any more. It is possible to keep in this interpretation a special place for parents, whom we cannot 'escape' from (without 'bruises'). We can agree that the longing for recognition is essential for everyone, and argue at the same time that from the moment someone does not offer any longer the desired recognition, he or she will be 'replaced'. Again we have to confront the facts. Taylor's second argument against purely instrumental relationships seems also not to hold true, the extreme case of course excluded. The narcissistic form of our present-day culture therefore does not seem to be as inadequate to the essence of a human being as Taylor expects us to infer.

Thus far two kinds of argument have been raised against Taylor's position. First, as a matter of empirical fact, that people do not act within a horizon of meaning, but may simply indulge a search for pleasure and immediate satisfaction. Social cocooning may encourage this. In a sense these facts are not good 'arguments' at all. They are precisely what Taylor is arguing against. But it cannot be denied that the twentieth century has produced this kind of humanity. Here 'what is' demands its rights, and that in turn has consequences for our concept of 'a human being'. Furthermore, this sheds a different light on the difference between leading a way of life and the possibility of offering a justification for it. Taylor's reflections highlight a particular kind of human being, who finds herself amidst significant others, within a common horizon of meaning, embracing and as far as possible choosing her commitments. Such a person is real and really honourable. There, Taylor finds the essence of human being, and therefore argues that subjectivism and narcissism are untenable. To me it seems meaningful - 
however sympathetic one might feel towards this kind of human being - to give up this essentialist claim, and I have offered conceptual arguments for doing so.

There is however something else that is made clear in Taylor's study (1991), briefly referred to at the beginning of this review. To argue for authenticity is also to argue for having the courage to declare one's convictions and to stand up for what one believes in. And this sheds more generally a different light on education.

In dealing with the concept of 'authenticity' Cooper once stressed the importance of being involved with a particular educational content and not just with an '. . . immersion in ways of thinking whose aim is to reach generalizations, to discover what items are instances of or data for ...' (Cooper, 1983, p. 67). For him, the supreme value '.. we must confer, then, is the value of giving-value-to; and what confers sense on life is giving-sense-to life. [Both are] . . the activities of individual human beings: indeed, they are the activities which manifest the supreme human capacities' (Cooper, 1983, p. 116). This kind of 'authenticity' does not discharge those concerned from the responsibility to justify themselves for what they are doing. For some, however, it is a value in itself, the value of being a certain kind of human being, one who goes through life honourably, straightforwardly, and faithfully to others and to what she believes in. To the authentic person, authenticity is compelling, and not valuing it would estrange her from herself. Analogously, on a more social level it can be argued for instance that communities that devote themselves to defending free speech quite evidently cannot remain silent when they are confronted with racist or anti-Semitic expressions. The right of free speech can also be used to denounce a disrespectful way of speaking of a part of the population by making clear that the only thing that the racist is really defending is her own interest at the cost of others.

Other authors have argued similarly. Rice and Burbules for instance have recently (1993) raised some doubts concerning the postmodernist trend to focus exclusively on ... . dissention, destabilization, and disturbance. . . . Education is, at least in part, the means by which social groups reproduce themselves; it entails availing the young of certain dispositions, values, and knowledge possessed by the adult members of the group into which they are born' (Rice and Burbules, 1993, p. 34). They call on everyone to practise communicative virtues such as being patient, tolerant and sincere with children, virtues that are not just passed on from parents to children. 'In the process of interacting with one another, children may be enabled to acquire the virtues, while adults' capacities for them may be sustained and strengthened' (Rice and Burbules, 1993, p. 42).

Arcilla (1992) argues analogously for an engagement in the 'educational relation and process' that goes beyond a fatalistic apathy and in this sense bears hope for the development of an individual or an improvement of society. Here the educator is conceived as the person characterised by integrity, who challenges the 'educandus'. The authentic individual, understood in a particular way, seems doubly relevant in an educational context: both for the educator, and for the 'educandus'. There remains a nucleus of personal responsibility both for Wittgenstein and for Taylor. This responsibility is grounded not in subjectivity but in intersubjectivity. This expresses itself in the responsibility of the educator for what she undertakes $v i s-\dot{a}$-vis the 'educandus', and in the appeal made by the 'educandus' to the educator when trying to determine his position. Taylor's stance asks us consequently to do what we say and to stand up for what we believe in. Again, it is not a solitary individual who is invoked in this stance, neither does it involve a radical (Sartrean) break with the past. In the light 
of what we are initiated into, what appeals to us and what makes us commit ourselves, we take up the gauntlet, personally and together with others. In doing this we give meaning to what we say and the way we act. And though Taylor's filling in of the concept of the authentic individual might be too strong to indicate for each and every one and for all circumstances what we have to do - and perhaps a better way to think of educational content might be given in terms of what 'we' (among them 'the educator') care for - it nevertheless incorporates an old and valuable ideal, which for many is the core of the idea of a person. To trivialise the content of education, as certain postmodernists propose, throws away in its radicalism all that is valuable in human history. It is not the case that we can start from scratch, neither is it clear why we should do so. A person seems to be moved by a questioning of life itself, and finds more than ever in her tentative answer what makes life valuable for her at all. In this sense we can go beyond what Arcilla has called fatalistic apathy; not from the certainty that we are right or that we will achieve certain results, but from a sincere inability to do anything else, an inability to abandon the 'educandus' to her or his fate.

It is unlikely but not impossible that in avoiding the pitfalls of narcissism Taylor's recent books mark the beginning of a new era: beyond postmodernism. ${ }^{2}$

Correspondence: Paul Smeyers, Katholieke Universiteit Leuven, Faculty of Psychology and Educational Sciences, Centre for Philosophy of Education, Tiensestraat 102, B-3000 Leuven, Belgium.

\section{NOTES}

1. References to this work are by pages only.

2. I am grateful to Nigel Blake, Reviews Editor, for comments and suggestions on an earlier version of this study and for his help with the correct English wording of my thoughts.

\section{REFERENCES}

Arcilla, R. V. (1992) Tragic absolutism in education, Educational Theory, 42, pp.473-81.

Cooper, D. (1983) Authenticity and Learning: Nietzsche's Educational Philosophy (London, Routledge \& Kegan Paul).

Giesecke, H. (1987) Das Ende der Erziehung: neue Chancen für Familie und Schule (Stuttgart, Klett-Cotta).

Kiziltan, M., Bain, W. and Canizares, A. (1990) Postmodern conditions: rethinking public education, Educational Theory, 40, pp. 351-69.

Rice, R. and Burbules, N. (1993) Communicative virtues and educational relations, Philosophy of Education, 48, pp. $34-44$.

Taylor, C. (1985) Philosophical papers (Cambridge, Cambridge University Press).

Wringe, C. (1993), Family values and the value of the family, in: Philosophy of Education Society of Great Britain: Papers of the 27th Annual Conference, Oxford, 16-18 April 1993, pp. 68-77. 